\title{
Posterior reversible encephalopathy syndrome and primary Sjögren's syndrome
}

\author{
Síndrome de encefalopatia posterior reversível e síndrome de Sjögren primária
}

Jacqueline Mori Lazzari', Maria Gabriela Lang ${ }^{1}$, Henrique Luiz Staub ${ }^{1} \bowtie$

${ }^{1}$ Department of Rheumatology, São Lucas Hospital, Pontifical Catholic University of Rio Grande do Sul (PUCRS). Porto Alegre, RS, Brazil.

How to cite this article:

Lazzari JM, Lang MG, Staub HL. Posterior reversible encephalopathy syndrome and primary Sjögren's syndrome. Sci Med. 2018;28(2):ID29837. http://doi.org/10.15448/1980-6108.2018.2.29837

KEYWORDS: Sjogren's syndrome; encephalopathies; brain disorders; autoimmune diseases.

DESCRITORES: Síndrome de Sjogren; encefalopatias; doenças cerebrais; doenças autoimunes.

Abbreviations: MRI, magnetic resonance imaging; PRES, posterior reversible encephalopathy syndrome; pSS, primary Sjögren's syndrome.

To the Editor,

Posterior reversible encephalopathy syndrome (PRES) is a disorder featuring headache, seizures, sensorium changes and visual loss. Autoregulatory failure with resultant vasodilation and edema, as well as vasospasm with ischaemic abnormalities, are both postulated in PRES pathogenesis. Parieto-occipital subcortical T2 hyperintensity without enhancement is a typical finding on magnetic resonance imaging (MRI) [1].

A link of PRES with autoimmune disorders, mostly systemic lupus erythematosus, has been proposed. We herein describe an unusual case of PRES in a patient with primary Sjögren's syndrome (pSS). This letter was written in accordance with the principles of the Helsinki Declaration as revised in 2013. Patients' identity was preserved, confidentiality and data protection were maintained, and all ethical principles of research involving human beings were respected.

The patient, a 58-year-old black male, was admitted due to mental confusion. Blood pressure was $142 / 100 \mathrm{mmHg}$. Brain MRI was typical of PRES in parieto-occipital lobes and cerebellum. In parallel, a lung infection caused by Pseudomonas aeruginosa was diagnosed. The patient recovered conscience with low-dose enalapril and antibiotics, and referred a long history of xerophthalmia, xerostomia, dry cough and polyarthralgia (with no previous treatment). Antinuclear antibodies (1/80 granular pattern), as well as anti-SSA antibodies and rheumatoid factor, were present. Electromyography disclosed a motor and sensitive axonal polyneuropathy. Ophthalmologic evaluation revealed keratoconjunctivitis sicca, and a minor salivary gland biopsy was compatible with pSS. After 15 days, and already on low-dose prednisone, the patient was well, and a new brain MRI was found to be normal. In the sequence, he developed acute abdominal pain requiring laparotomy. Two perforated duodenal ulcers were disclosed. After surgery, the patient evolved with an enterogastric fistula and died due to septicemia.

PRES is a nebulous disorder triggered by a number of conditions, mostly hypertensive crisis, renal insufficiency, and immunosuppressive therapy. Other possible etiologies include eclampsia, transplantation 
and infections [1]. The association of PRES with autoimmune disorders has been rather intriguing. Out of 120 cases of PRES, autoimmune disorders were identified in as much as $45 \%$ of individuals [2]. The disorder has been particularly described in systemic lupus erythematosus, being eventually considered a neurological manifestation of lupus itself [3]. Our group reported two cases of PRES and systemic lupus erythematosus in different scenarios: one patient developed PRES after steroid "pulse therapy", and the other in concomitance with infection [4]. A link of PRES with pSS, nevertheless, is far from usual.

This patient showed a broad spectrum of pSS, which is a chronic multisystemic disease, including keratitis, articular pain, polyneuritis, and autoantibodies. A quarter of the patients with pSS have neurological manifestations; polyneuropathy and demyelinating encephalopathy or myelopathy are well-recognized [5]. It is hypothetical if PRES can be interpreted as a neurological manifestation of previous pSS in the current case, in which a distinctive role for pSS in PRES may have been clouded by recent hypertension and lung infection. At the same time, it is difficult to ruled out a pSS-related brain inflammation as a trigger for PRES in this patient. In a 2015 Korean case report, PRES was described as an initial manifestation of pSS [6]. Thus, this is probably the second report associating PRES and pSS.

In summary, we herein report a PRES in a patient with pSS, hypertension and lung infection. If PRES was triggered by pSS itself or by comorbidities remains an open question. Further studies are warranted to clarify the link between PRES and pSS.

\section{NOTES}

Funding

This communication did not receive financial support from outside sources.

Conflicts of interest disclosure

The authors declare no competing interests.

Authors' contributions

All the authors declare to have made substantial contributions to the conception, or design, or acquisition, or analysis, or interpretation of data; and drafting the work or revising it critically for important intellectual content; and to approve the version to be published.

Availability of data and responsibility for the results

All the authors declare to have had full access to the available data and they assume full responsibility for the integrity of this report.

\section{REFERENCES}

1. Lamy C, Oppenheim C, Mas JL. Posterior reversible encephalopathy syndrome. Handb Clin Neurol 2014;121:1687-701. https://doi.org/10.1016/B978-0-7020-4088-7.00109-7

2. Fugate JE, Claassen DO, Cloft HJ, Kallmes DF, Kozak OS, Rabinstein AA. Posterior reversible encephalopathy syndrome: associated clinical and radiologic findings. Mayo Clin Proc 2010;85:427-32. https://doi.org/10.4065/mcp.2009.0590

3. Ishimori ML, Pressman BD, Wallace DJ, Weisman MH. Posterior reversible encephalopathy syndrome: another manifestation of CNS SLE? Lupus 2007;16:436-43. https://doi.org/10.1177/0961203307078682

4. Marrone L, Streck A de S, Staub HL, de Freitas CZ, Costa J, Gadonski G, Staub HL. Posterior reversible encephalopathy syndrome (PRES) and systemic lupus erythematosus: report of two cases. Rev Bras Reumatol. 2012 Oct;52(5):804-10. Erratum in: Rev Bras Reumatol. 2013 Feb;53(1):132. http://dx.doi.org/10.1590/S0482-50042012000500016

5. Fauchais AL, Magy L, Vidal E. Central and peripheral neurological complications of primary Sjögren's syndrome. Presse Med 2012;41(9 Pt 2):e485-93. https://doi.org/10.1016/j.lpm.2012.06.002

6. Jeong HN, Suh BC, Kim YB, Chung PW, Moon HS, Yoon WT. Posterior reversible encephalopathy syndrome as an initial neurological manifestation of primary Sjögren's syndrome. Clin Auton Res. 2015;25:259-62. https://doi.org/10.1007/ s10286-015-0305-y $€$ 